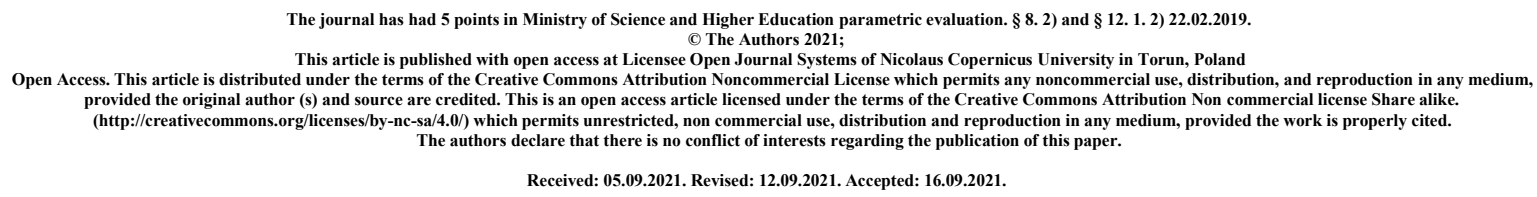

\title{
Influence of feed additives for chickens on the quality of eggs laid and related risks
}

\author{
Magdalena Wasielewska; ORCID: 0000-0001-8638-3732; E-mail: \\ w.magdalena1@gazeta.pl
}

Institution: Nicolaus Copernicus University in Toruń Collegium Medicum in Bydgoszcz, ul. Jagiellońska 13-15, 85-067 Bydgoszcz, Major Pharmacy

Key words: antibiotics, phytobiotics, antibiotic growth stimulants, chicken eggs, poultry

\begin{abstract}
A chicken egg is a valuable animal product that has served people for centuries. Research carried out over the last dozen or so years shows that society's knowledge about them is still relatively small. The research cited in the text shows that only $23 \%$ of respondents know that the color of a hen's egg shell depends on the breed of the hen, and not on the way it is fed. As a result, some consumers choose eggs in the store by choosing their color instead of the official markings on each individual egg. Chickens' nutrition has a direct impact on the quality of the eggs they lay. Chickens fed with fodder with antibiotics lay eggs in which we can find the same antibiotics that the animal ate with the food. It has many side effects, however, the greatest of which seems to be bacterial drug resistance, caused by the use of the same strong antibiotics in the nutritional industry and in human hospital medicine. Bacteria have developed various resistance mechanisms. For example, Enterococcus spp. Has developed resistance to vancomycin, Salmonella Typhimurum to tetracyclines, sulfonamides and fluoroquinolones. However, it is possible to use antibiotics in poultry treatment, but it is very important in this case to strictly observe the grace periods necessary to eliminate the
\end{abstract}


antibiotic from the animal's body. Some of the world's governments, aware of the dangers of such a state of affairs, are trying to combat the phenomenon of feeding poultry with antibiotic growth stimulants by introducing new norms, orders and bans in their countries. Antibiotics such as avoparcin, zinc-bacitracin and spiromycin have been discontinued. Chicken egg producers are finding newer and newer ways to circumvent these recipes. Non-antibiotic feed additives such as probiotics, phytobiotics, and specific herbs are used. An effective way to combat this phenomenon may be to educate the public on this topic.

\section{Composition of a chicken egg}

A chicken egg is an excellent natural food product. Macroscopically, the egg consists of three main structures: proteins (about 60\%), yolks (about 30\%) and shells (about 10\%). It is chemically composed of water (75\%), protein $(12 \%)$ and lipids $(12 \%)$, and it also contains minerals, vitamins and phospholipids. Important nutrients are n-3 and n-6 unsaturated fatty acids. Skorupka, on the other hand, is a mine of minerals such as: first of all calcium, then boron, chromium, copper, iron, iodine, manganese, sulfur, selenium, silicon, and zinc. [1, 2]

\section{Egg markings in Poland}

Each Polish egg from a registered breeding farm has a stamp with a sequence of characters on it - for example, let's assume that it is:

0-PL-11223344

a) First marking - marking of laying hens rearing

0-PL-11223344

There are 4 systems of keeping laying hens in Poland. Each system is assigned a number that should be on the egg. It is the first digit of the number printed on each egg:

- (0) - organic farming - hens move freely on the run. Poultry houses are located in areas characterized by low harmfulness. The maximum number of specimens may not 
exceed 3,000 in one holding. The hens are fed with fodder from organic farming. The use of antibiotics is prohibited. Food cannot be synthetic or genetically modified. It is allowed to use natural plant preparations to increase immunity, probiotics and vaccines. [3]

- (1) - free-range breeding - in addition to housing, hens may stay outdoors during the day, and each of them should have at their disposal at least $4 \mathrm{~m} 2$ of space.

- (2) - bedding rearing - hens are kept in rooms where at least $33 \%$ of the area should be covered with litter. Sockets can be arranged on several levels. The hens move freely around the hall. There may be 9 layers per $1 \mathrm{~m} 2$ of the area.

- (3) - cage rearing - new regulations apply to this type of rearing, which increase the required number of cages so that the width of the cage without the nest is at least 30 $\mathrm{cm}$, and the height is at least $45 \mathrm{~cm}$. It is required that there is a nest, perches and bedding in the cage. It is possible thanks to chicken pecking and rummaging [4].

Backyard farms are exempt from marking eggs, and then they are sold at bazaars or markets.

b) Second position - designation of the country in the European Union

0-PL-11223344

The next item in the egg number (PL) is, as you can guess, the designation of the country in the European Union.

c) Third, fourth, fifth and sixth items

0-PL-11223344

- -11 - voivodship code,

- -22 - county code,

- 33 - scope and type of the company's activity,

- $\quad$ - 44 - farm code in a given poviat.

\section{Consumer knowledge of egg labeling}

In 2010, research was conducted on the public's knowledge of

food products. The study group was a stratified sample of the country's inhabitants over 
15 years of age. The obtained results were run through an algorithm based on the results of the survey of the Economic Activity of the Population from the third quarter of 2009 carried out by the Central Statistical Office.

In the nationwide sample, $22 \%$ of people correctly indicated the egg markings. A greater number of women, as much as $26 \%$, compared to men (19\%), correctly read the markings of organic eggs. There is a relationship between the education level and the frequency of correct answers. This relationship is as follows: the correct answer was given by $18 \%$ of people with primary education, $25 \%$ of people with secondary education and $32 \%$ of people with higher education. The differences in the number of correct answers were also noticeable between the society living in large cities (36\%) and villages as well as small and medium-sized cities (21\%, $19 \%$ and $15 \%$ respectively). An important aspect of consumer awareness is the aspect related to the frequency of daily purchases by individual age groups. Hence, people aged 22-65 gave correct answers more often than younger or older people. [5]

Using the online questionnaire form, a study was conducted to assess the preferences of egg consumers in the Lublin region. It has been shown that consumers most often choose medium or large eggs, beige or light brown in color and yolk colored to a color corresponding to 8 points on the Roche scale (sunny yellow). It was also noticed that consumers indicated incorrect relationships between the color of the yolk and its taste and health benefits. The available research and literature indicate that consumers do not have adequate knowledge about egg raw material. [6]

\section{The relationship between the color of the hens' plumage and the color of the eggshells}

\section{laid by them}

The main division in terms of the color of plumage is the division into hens with white and colored plumage. White plumage is a genetic trait, but the way it is inherited differs from breed to breed.The hawkish color of the plumage is a gender-linked feature. Mutations also affect the color of the feathers of these animals. For example, mutations in the melanotropic hormone (MSH) and its receptor where multiple loci are involved in coding. Pigmentationproducing genes have a pleiotropic effect on the development and differentiation of the organism. [7]

KoThe lor of the eggshell depends on the breed of the hen. Generally speaking, it can be stated that the eggs from the darkly feathered hens are darker, from the lightly feathered ones they are slightly lighter, and from the white ones they are white. Both features - the color of the plumage and the color of the egg shell have been the subject of many studies and are 
features determined by many genes. $[8,9,10]$

\section{Consumers' awareness of the relationship between the color of the plumage and the color of the eggshell}

The research results show that as many as $45 \%$ of people with higher education and $28 \%$ with secondary and primary education believe that the color of the eggshell depends on the chicken's nutrition, which may translate into the preferences of these consumers when buying eggs. Only about $23 \%$ of respondents correctly indicated that the color depends on the breed of the hen. The color of the eggshell does notaffects its taste, but research has shown that consumers prefer eggs with specific colors. In Poland, eggs with a dark shell are most often bought, while in the USA, eggs with a white shell are preferred. Research by Johnston et al. Has shown that consumers believe that eggs are healthier and contain more nutrients. [11]

\section{Normal feeding of chickens}

Numerous studies show that bird nutrition significantly influences the development of egg content quality traits (Hammershøj and Kjaer, 1999; Balnave et al, 2000; Franchini et al. 2002; Krawczyk and Gornowicz, 2010; Demola et al. 2012).

According to the data in the literature, we know that oats and barley have a positive effect on the ratio of dense protein to the rare egg white, in contrast to wheat and maize.

However, the protein content of cereal grains is too low to meet the nutrient requirements of laying hens. Therefore, compound feed must be balanced by using significant amounts of high-protein materials.

The most important material increasing the proportion of protein is imported soybean extraction meal, derived from genetically modified (GM) soybeans. Soybean meal is a highprotein feed, containing approx. $45 \%$ of total protein. The amount of anti-nutritional compounds in soybean meal is small, so this material can be used in poultry feed with virtually no restrictions. [12, 13].

Due to the physiology of the gastrointestinal tract of birds, as well as the high demand of poultry for good-quality protein with a favorable amino acid composition, complete replacement of soybean extraction meal is very difficult $[14,15]$.

Rapeseed cake has become more and more popular in the last decade. Both of these feed materials are by-products of the fat industry that remain after the extraction of oil from rapeseed. A characteristic feature of the proteins of these products is the high content of essential amino acids, such as methionine and threonine, with a low proportion of lysine. The 
digestibility of amino acids may be reduced due to the effect of temperature during the heating of the seeds.

There are anti-nutritional factors such as glucosinolates and erucic acid in the abovementioned soybean meal and rapeseed cake, but their content in rapeseed " 00 " has been lowered to safe values. Moreover, heating the seeds during their processing inactivates the enzyme myrosinase, which breaks down glucosinolates into harmful compounds. Another anti-nutritional factor in oilseed rape is sinapine. The product of its decomposition in the body is trimethylamine, a compound that may worsen the sensory characteristics of eggs in layers that lay eggs with brown shells.

\section{Glucosinolates in poultry nutrition}

Glucosinolates contained in the diet of poultry have a positive effect on the growth and performance of birds, and are more harmful to laying hens than broilers. Campbell et al [16] found that the hydrolysis of glucosinolates in the digestive tract of chickens is faster in the mixture without the addition of antibiotics, and slower in the mixture of feed with antibiotics. [17]. The content of glucosinolates in mixtures for poultry should not exceed $1.5 \mu \mathrm{M} / \mathrm{g}$ of mixture, with older birds being less sensitive than younger ones. The high proportion of glucosinolates in the diet of poultry may lead to a reduction in feed consumption, growth disorders and an increase in mortality [18].

\section{The madness of overproduction}

The number of people in the world is growing very fast, hence the global economy still has to struggle with the problem of constantly increasing demand to meet the demand. Keeping poultry in a cage system is associated with a very high probability of an epidemic in the population of chickens, due to the large number of individuals living in a small space. That is why antibiotics have been introduced into breeding, which allow to achieve a much higher productivity of poultry.

\section{Antibiotics in poultry nutrition}

The prophylactic introduction of antibiotics into poultry feed was an attempt to protect them against disturbances in the microbiological balance in the digestive tract. Subsequent studies have shown that the addition of antibiotics to feed increases growthbody weight of birds with a reduction in food doses, thus increasing the efficiency of animal production and reducing its costs. These supplements have become known as antibiotic growth promoters, 
abbreviated as ASW.

Antibiotics registered as growth promoters in the European Union include: penicillins, chlortetracycline, oxytetracycline, zinc-bacitracin, flavophospholipol, virginiamycin, erythromycin, spiromycin, and avoparcin (vancomycin analogue) [19].

\section{The problem of drug resistance in humans caused by the administration of antibiotics to}

\section{laying hens}

In 1969, in the so-called The Swann report describes the problem of antibiotic resistance associated with the use of antibiotics in animal husbandry. It also highlights the division into feed antibiotics - more widely available and therapeutic - only with a veterinarian's prescription. This led to the withdrawal of the use of such antibiotics as penicillin, streptomycin, and tetracyclines [20, 21].

Resistance mechanisms such as vancomycin resistance have developed in bacteria over time. Vancomycin is used in humans to treat infections with bacteria from the groupEnterococcus spp. Is also a last resort antibiotic for the treatment of MRSA infections. $[22,23]$. Relationships between the use of antibiotic growth promoters and the emergence of resistance in enterococci and other gram-positive bacteria have also been described for avoparcin, which is an analog of vancomycin [24], avilamycin [25], and bacitracin and streptogramin [26].

Withdrawal of antibiotic growth promoters reduced the frequency of resistance genes in indicator bacteria, Escherichia coli and Enterococcus spp. At the same time, however, the need for antibiotics to treat animals increased, which led directly to an increase in resistance to bacteria such as Salmonella, Campylobacter, for example S. Typhimurum developed resistance to tetracyclines, sulfonamides, and fluoroquinolones [27].

\section{The presence of antibiotic residues in chicken eggs}

The presence of antibiotics in eggs can have two effects on the consumer. Direct, i.e., for example, affecting the human body in the form of causing allergic reactions, influencing the intestinal microflora and generating microbial resistance, and indirect, through improper sanitary and veterinary assessment of food of animal origin by influencing the results of microbiological tests. Studies have shown that it is possible to avoid the negative effects of the use of antibiotics in poultry food by following the principles of good husbandry and veterinary practice. The most common reason for the presence of antibiotics in animal products is failure to comply with the grace periods necessary for the elimination of the drug 
from the animal's body and the dosing of drugs that is inconsistent with the indications. The arbitrary administration of antibiotics by breeders is also an important reason. At the same time, it cannot be ruled out that the reports of SAW in chicken eggs do not refer directly to ASW, but may indicate traces of therapeutic antibiotics.previously used to treat animals [28, 29].

\section{Banning the use of antibiotic growth promoters}

The drug resistance of bacteria is still growing, hence individual EU countries have gradually started to withdraw from the use of ASW. Sweden was the first country to introduce such a ban in 1986. It was followed by other Scandinavian countries: Norway and Denmark in 1995. The rest of the European Union then followed the example of Scandinavia. The use of antibiotics used in medicine as feed additives was banned. Initially, the ban only concernedavoparcin, and then zinc-bacitracin, spiromycin, tyrosine and virginiamycin [30]. In 2003, Regulation No. 1831/2003 on feed additives was issued, which sealed the process of phasing out ASW [31]. Pursuant to this regulation, the remaining antibiotics that could be used as ASW, i.e. avilamycin, flavophospholipol, were withdrawn on January 1, 2006.

\section{Consequences of the ban on the use of antibiotic growth promoters}

The import of animal products from countries where the use of ASW was not prohibited was limited, so it had a positive effect on increasing the competitiveness of animal food products from EU countries [32]. As a result, consumers have a wider choice of goodquality products that do not adversely affect their health.

Unfortunately, at the same time, the consumption of antibiotics used for therapeutic purposes has increased, such as: macrolides, tetracyclines and beta-lactams [33]. These are groups of antibiotics used on a large scale in human treatment, which dangerously correlates with the great risk of developing resistance to very dangerous bacteria, such as: Salmonella, Campylobacter and zoonotic strains of Escherichia coli.

Of course, the animal breeder was not at hand to give up substances that allowed them to achieve enormous productivity, so over time, new additives began to be searched for that could be an alternative to antibiotic growth stimulants and also effectively stimulate more efficient production.

\section{Non-antibiotic feed additives}

The interest in herbal supplements in poultry nutrition is growing year by year. The 
addition of herbs makes the nutrients are more effectively broken down into easily digestible substances. They have a positive effect on the bird's digestive tract, reductionintestinal problems, they have a stimulating effect on the liver and pancreas. They also contribute to the increased weight gain of the poultry.

Preparations of plant origin, that is, differently Phytobiotics are considered to be natural and safe additives, unlike ASW. Currently, research is being carried out on the influence of plants, which are assigned antioxidant properties. These can include, among others lemon balm, sage and nettle. (Marcinčáková et al., 2011; Kasapidou et al. 2014; LopezBote et al. 1998; Wereńska 2013; Bonetti et al., 2016).

They have become a popular addition to animal feed probiotics, i.e. bacteria (most often from the group of lactic acid bacteria) and a few fungi. Among the first, bacteria of the genus Lactobacillus, Lactococcus, Streptococcus, Enterococcus and Bifidobacterium are most often used, while the fungi include Saccharomyces cerevisiae and boulardii, Aspergillus oryzae and niger [34]. The health-promoting mechanism of probiotics on animals depends on the age of the animals, their physiological state, the type of production and environmental conditions. Many authors point to the important mechanism of action of probiotics related to the colonization of the gastrointestinal tract and thus the improvement of feed digestibility. When administered in an appropriate amount, they should improve the animal's health condition and stimulate its growth $[35,36]$. The metabolites of probiotic bacteria have a beneficial effect on the host organism [37, 38].

The relationship they discovered is interesting Kalsum et al. Investigating the influence of Lactobacillus fermentum on egg quality. In the group of chickens fed with probiotics, an increase in egg production index by as much as $14.95 \%$ compared to the control group was observed, and egg yolks had less cholesterol [39].

Application probiotics has been regulated by law. For Lactobacillus, eight species have been authorized in the EU as feed additives for farm animals [40].

However, the most compelling argument for use of probiotics in poultry nutrition is the fact that pro-biotic bacteria are able to affect other bacteria in the digestive tract, including pathogenic ones, and thus they are able to reduce harmful microbiota through the phenomenon of displacement, as well as bactericidal and bacteriostatic effects [41]. At the same time, in addition to protecting against pathogens, they can also increase the body's immunity, contribute to better absorption of digested food, and extend the life of the animal through the synthesis of polyamines [42]. 


\section{Summary}

A chicken egg is an irreplaceable food product in cuisines all over the world. Its quality is very important, and it is most influenced by the feeding of laying hens with appropriate food that does not contain any antibiotics. Consider whether the available phytobiotics and probiotics do not pose a threat to animals and humans, indirectly through animal products. Unfortunately, consumer awareness of the origin of the eggs, the nutrition of the chickens that lay them and the general basic knowledge of the raw material is frighteningly low. Lack of such awareness leads to consumers still buying eggs from cage farms in which antibiotics are used, and this directly contributes to the constant need to deal with the problem of drug resistance of bacterial strains particularly dangerous to humans.

\section{Literature}

1. Trziszka T., Różański H., Polanowski A., 2013, Eggs as a very promising Skurce of biomedical and nutraceutical preparations: a review, J. Life Sci 7: 862-877.

2. Walczak J., Bocian S., Trziszka T., Buszewski B., 2016, Hyphenates analytical methods in determination of biologically active compounds in hen`s eggs, Crit. Rev. Anal. Chem. 46: 201-212.

3. Commission Regulation (EC) No. 889/2008 of September 5, 2008. laying down detailed rules for the implementation of Council Regulation (EC) No 834/2007 on organic production and labeling of organic products with regard to organic production, labeling and control.

4. Regulation of the Minister of Agriculture and Rural Development of February 15, 2010. on the requirements and procedure for keeping farm animal species for which protection standards have been defined in the regulations of the European Union (Journal of Laws 2010.56.344).

5. Kowaliszyn B., Sitkowska B., Mroczkowski S., 2012, Consumer knowledge and beliefs about chicken eggs, University of Technology and Life Sciences in Bydgoszcz, breeding review No. 7-9 / 2012.

6. Wengerska K., Woronowa A., Wajcht A., Wargala E., 2020, Consumer preferences in the Lublin region, In: Research and Development of Young Scientists in Poland, Life Sciences - fauna and animal husbandry (pp. 102-108), Publisher : Young Scientists, Poznań.

7. Charon K., Świtoński M., 2000, Animal genetics, Wyd. Science. OWN. 
8. Liu WB, Chen SR, Zheng JX, Qu LJ, Xu GY, Yang N., 2010, Poult Sci. 89: 11101114.

9. Moreno J., Osorno JL, Morales J., Merino S., Tomas G., 2004, J. Avian Biol. 35: 300304.

10. Zhang LC, Ning ZH, Xu GY, Liu ZZ, 2006, Poult. Sci. 85: 546-549.

11. Johnston NP, Jefferies LK, Rodriguez B., Johnston DE, 2011, Pult. Sci 90 (5): 10741079.

12. Brzóska F., Śliwinski B., 2018, The influence of feed enzymes on the productivity, carcass quality and intestinal digestibility of amino acids in broiler chickens fed diets containing post-extraction rapeseed meal, Rocz. Science. Zoot., 45: 25-48.

13. Michalik-Rutkowska O., Brzóska, F., Pietras M., Śliwiński B., 2017, The effect of conversion of post-extraction soybean meal with rapeseed cake in diets for broiler chickens on body weight, carcass quality and apparent intestinal digestibility of amino acids, Rocz. Science. Zoot., 44: 223-246.

14. Reichert M., Kozaczyński W., Karpińska TA, Bocian Ł., Jasik A., Kycko A., Świątkiewicz M., Świątkiewicz S., Furgał-Dierżuk I., Arczewska -łosek A., Strzetelski J., Kwiatek K, 2012, Histopathological study of internal organs of experimental animals fed with genetically modified corn and soybean meal, Bull. Vet. Inst. Pulawy, 56: 617-622.

15. Szczurek W., 1997, Preliminary evaluation of the effectiveness of feed enzymes in the feeding of fattening chickens with a mixture with a high proportion of overheated rapeseed meal.

16. Campbell LD, Slominski BA, Stanger NE, 1987, Influence of cecectomy and diet ary antibiotics on the fate of ingestes intact glucosinolates in poultry, Proceedings 7 th International Rapaseed Congress, Poznań, 1704-1709.

17. Smulikowska S., 2002, The brown color of egg shells limits the use of rapeseed forage in laying hens nutrition, Pol. Poultry. 12: 18-19.

18. Palander S., Näsi M., Ala-possi I., 2004, Rapeseed and soybean products as protein surces for growing Turkey of different ages, Brit. Poultry. Sci. 45: 664-671.

19. Różańska H., 1999, Doctoral dissertation. The influence of antibiotic residues on the results of microbiological tests, Puławy.

20. Van den Bogaard AE, Stobberingh EE, 2000, Epidemiology of resistance to antibiotics. Links between Animals and humans, Int. J. Antimicrob. Agenst. 14: 327335. 
21. Wegener HC, 2003, Antiobiotics in Animals feed and their role in resistance development, Curr. Opin. Microbiol. 6: 439-445.

22. Bates J., Jordens JZ, Griffiths DT, 1994, Farm Animals as a putative reservoir for vankomycin resistant enterococcal infection in Man, J. Antimicrob. Chemother. 34: 507-516.

23. Robredo B., Singh KV, Baquero F., Murray BE, Torres C., 2000, Vankomycinresistant enterococci isolated from Animals and food,Int J Food Microbiol. 54 (3): 197-204.

24. Bager F., Madsen M., Christensen J., Aarestrup FM, 1997, Avoparcin used as a growth promotor is associated with the occurrence of vankomycin-resistant Enterococcus faecium on Danish poultry and in pig farms, Prev. Vet. Med. 31: 95-112.

25. Aarestrup FM, 1998, Association between decreased susceptibility to a New antibiotic for treatment of human diseases everninomycin, and resistance to an antibiotic used for growth promotion in an Animals, avilamycin, Microbial Drug Resistance Mechanisms Epidemiology and Disease 4, 137-141.

26. Aarestrup FM, Kruse H., Tast E., Hammerum AM, Jensen LB, 2000, Associations between the use of antimicrobial agents for growth promotion and the occurrence of resistance among Enterococcus faecium form broilers and pigs in Denmark, Finland and Norway, Microbial Drug Resistance 6: 63-70.

27. Delsol AA, Randall L., Cooles S., Woodward MJ, Sunderland J., Roe JM, 2005, Effect of the growth promoter avilamycin on emergence and persistence of antimicrobial resistance in enteric bacteria in the pig, J. Appl. Microbiol. 98: 564-571.

28. Różańska H., 2012, Antibiotic residues in food in terms of their inappropriate use in animals, In: Veterinary pharmacy in Poland - rational use of antibiotics - science and practice, Puławy.

29. Posyniak A., 2012, Antibiotics in food - presence and control of residues. In: Veterinary pharmacy in Poland - rational use of antibiotics - science and practice, Puławy.

30. Council Regulation (EC) 2921/98 of December 17, 1998. amending, with regard to the withdrawal of authorizations for certain antibiotics, Directive 70/524 / EEC concerning feed additives.

31. Regulation (EC) $1831 / 2003$ of the European Parliament and of the Council of 22 September 2003 on additives for use in animal nutrition. 
32. Koreleski J., Świątkiewicz S., 2006, Ban on the use of feed antibiotics - what next? Pasze Przemysłowe 2/3: 22-29.

33. DANMAP: Use od antimicrobial agents and occurrence of antimicrobial resistance in bacteria from food Animals, foods and humans in Denmark. Danish Institute for Food and Veterinary Research, 2004.

34. Janik A., Koska M., Paluch U., Pieszka M., Barowicz T., 2006, Zootechnical News, R, XLIV, 1, 3-9.

35. Ezema C., Chukwuemeka E., 2012, Comperative Clinical Pathology 21 (1): 73-76.

36. Lipiński K., Kaliniewicz J., Tywończuk J., Stasiewicz M., 2011, Scientific Annals of the Polish Society of Animal Production 7 (2): 29-35.

37. Libudzisz Z., 2008, Lactic fermentation bacteria, In: Technical microbiology (ed. Z. Libudzisz, K. Kowal, Z. Żakowska), T.2. He will publish Science. PWN, Warsaw.

38. Śliżewska K., Biernasik J., Libudzisz Z., 2006, Scientific Papers of the Lodz University of Technology, Food chemistry and Biotechnology 984 (70): 79-91.

39. Kalsum U., Soetanto H., Achmanu., Sjofjan O., 2012, International Journal of Pultry Science, 11 (4): 311-315.

40. Zhou Z., Wang W., Liu W., Gatlin DM, Zhang Y., Yao B., Ringo E., 2012, Aquaculture, 370-371, 150-157.

41. Vidal M., Forestier Ch., Charbonnel N., Henard S., Rabaud Ch., Lesens O., 2010, Journal of Clinical Microbiology, 48 (7): 2595-2598.

42. Matsumoto M., Kurihara S., Kibe R., Ashida H., Benno Y., 2011, PloS ONE, 6 (8): 112. 